\title{
DE LA PROCEDENCIA Y EL USO DEL CÓDICE MADRID (TRO-CORTESIANO)
}

\author{
Marichi.a Ayal.a Fal.cón \\ Centro de Estudios Mayas, IIFL, UNAM
}

Son ampliamente conocidas entre los interesados en la cultura maya las diferentes etapas por las que ha atravesado el desciframiento de su escritura jeroglífica. La historia está relatada en múltiples textos y no voy a incidir en ella, pero forzosamente tengo que referirme a dos escuelas de análisis que, por desgracia, casi se convirtieron en estandartes para aquellos epigrafistas que, de alguna manera, se encontraron con la necesidad de preferir uno u otro método.

Me refiero al viejo problema inventado por los mismos epigrafistas sobre qué era más importante: el calendario o la escritura, y digo inventado porque sabemos que todos los textos contienen ambos tipos de registros: el calendárico (las fechas) y el escrito (los textos), con algunas excepciones que ocurren en el Códice Madrid, en donde están las fechas pero no hay escritura, sólo imágenes que, finalmente, conllevan en sí mismas un mensaje.

Es verdad que durante los primeros cien años en la historia del desciframiento se le dio prioridad a los contenidos calendárico y astronómico, pero también lo es que en los últimos cuarenta, al encontrarse el contenido histórico de los monumentos e identificarse el valor fonético-silábico y logográfico de la escritura, la parte calendárica ha pasado a un segundo plano, viéndosele actualmente como un somero marco temporal, casi siempre enfocado al modo occidental por los epigrafistas. Es decir, como eventos que se suceden linealmente para explicar los hechos políticos llevados a cabo por los autores de los textos, sin prestar atención al hecho de que entre guerra y guerra ocurrían hechos que a los historiadores mayas les interesaba dejar consignados mediante el calendario y la escritura.

Cuando se tiene la oportunidad de adentrarse en estos textos no deja de sorprender el manejo tan especial que hacían los mayas con las fechas y cómo buscaban, especialmente en lugares como Palenque, conciliar los hechos con las fechas $\mathrm{y}$, todavía más, colocar esa información de manera artistica, por ejemplo. es muy interesante que para los palencanos la Diosa Madre nació en un día 8 Ahaw, el baktun 9, y esto si es real, inició en 8 Ahaw y, lo más importante, K'inich Hanab Pakal nació en 8 Ahaw. Si además analizamos el Tablero de la Cruz. en su parte mítica notamos que la fecha $9 \mathrm{lk}$ fue de gran interés para el autor del documento, Kan Bahlam Il, pero también se da uno cuenta de que la ubicación 
de los cartuchos no está puesta al azar, cada uno ocupa un lugar preciso. Así, en el Tablero de la Cruz los cartuchos que se localizan al final de las seis primeras columnas repiten la misma información, se trata del verbo $\mathrm{T} 740,{ }^{1} \mathrm{SIH}^{2}{ }^{2}$ "nacer", seguido por el sujeto respectivo en cada caso (figuras 1 a y 1 b):
$\mathrm{A} 17-\mathrm{B} 17$
SIH-ya-ja je-NA ${ }^{3}$
C17 - D 17
i-SIH-il ma-ta-ni-li ${ }^{4}$
si (h)yaj Je Na
$\mathrm{E} 17-\mathrm{F} 17$
SIH-ya U-KIIX-CHAN
i si (h)il Matanil
si (h)i U Kiix Chan

"nació la Señora", "su nacimiento del heredero", "nace El Espina Serpiente".5

Lo mismo ocurre con los códices, las fechas conforman lo que llamo el "esqueleto" de los textos, porque es lo que los estructura, tanto en monumentos como en códices, todas las oraciones inician con una fecha o un adverbio temporal. En el caso de los códices Dresde, Madrid y Paris, ${ }^{6}$ el año de 260 dias constituye la parte medular de los tres, pero hay diferencias entre ellos, por ejemplo, en el Madrid (como veremos mas adelante) algunas fechas están abreviadas y no hay de las Ilamadas de Cuenta Larga, como ocurre en los otros dos que, por presentar información de índole astronómica, si las contienen.

También presentan diferencias caligráficas, lo cual ha llevado a los estudiosos a considerar uno más perfecto que los otros. Tales comparaciones se han hecho especialmente entre los códices Dresde y Madrid: "Artísticamente, el códice de Dresde es muy superior a los códices de Madrid y de París" (Thompson, 1983: 40). Pero esto no debe tomarse como un juicio contundente, es como si se dijera que la escritura de Chichén Itzá por ser menos elegante que la de Palenque resta valor a la información que transmite, o que porque la protohistórica egipcia es más bella que el alfabeto latino, ésta es más funcional. Lo importante, finalmente, es que todas transmiten sus mensajes de manera plena.

El problema con dicha comparación entre el Dresde y el Madrid acarrea otra cuestión, pues no es solamente que se diga: "mi códice es más bonito que el

\footnotetext{
'La letra Ty el número șe refieren al glifo respectivo en el Catálogo de Enic Thompson (1962).

${ }^{2}$ El glifo T740 tiene dos propuestas de lectura, hu, "llegar" y sih, "nacer, una dádiva". Para este caso he conservado la lectura sih ya que corresponde al sentido que mantiene en el texto de Palenque.

${ }^{3}$ El glifo T1000 ha sido identificado como indicador del género femenino y se le han asignado

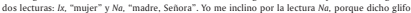
sustituye al número 1, que también se lee no. Además, las mujeres mayas solamente aparecen en los textos glificos cuando son la madre de alguien.

${ }^{4}$ Este cartucho ha sido leido ma-ta-wi-li, matawil, pero no tiene traducción. Después de revisar con mucho cuidado el monumento original se puede apreciar que el postfijo se asemeja mas al ni. por lo que desde hace tiempo he propuesto la lectura motonil. con el significado de "heredero". "Maton, lo así recibido de gracia o de limosna o lo impetrado o alcanzado de gracia" (Diccionario Cordentex: 505-506). Compárese esta traducción con el significado de sih̆, "nacer, una dádiva".

${ }^{5}$ En estos casos el escriba parece ser el mismo, pero cambia en la segunda parte cuando empieza la mano de otro escriba, como puede observarse en los "bigotes" que le agrega a la iguana.

${ }^{6}$ No incluyo al Grolier porque, en mi opinión, no se ha comprobado totalmente su autenticidad.
} 
tuyo", es más serio que esto porque se ha llegado a declarar al Madrid como un códice posthispánico (Coe y Kerr, 1997), afirmación que, si se analiza detenidamente, conlleva implicaciones que van mas alla de la posible fecha de su producción.

El Códice de Dresde fue el primero que se conoció, gracias a Alexander von Humboldt (1810) y después a la recopilación de códices que hiciera Edward King, Lord Kingsborough, en su obra Mexican Antiquities (1831-1848). Con ello de alguna manera se inició el estudio de la escritura jeroglifica maya (Constantine Rafinesque, 1827-1833), como señalara Günter Zimmermann (1964).

El Códice Madrid, o Tro-Cortesiano, tuvo una historia diferente, ya que no fue sino hasta 1869-1870 que se publicó la sección conocida como Códice Troano, por el abad Charles Ettienne Brasseur de Bourbourg, quien además habia localizado los fragmentos que actualmente conocemos como Relación de las cosas de Yucatán, escritos por fray Diego de Landa, donde se encuentra el ahora famoso alfabeto maya, así como su explicación sobre el calendario.

Fue con este alfabeto que Brasseur (1869-1870) trató de leer el Troano y. como hoy se sabe, identificó y leyó acertadamente un glifo muy importante (T1). el correspondiente al fonema u, "él", pronombre de tercera persona del singular, ya que la mayor parte de los textos glíficos mayas están escritos en tercera persona. Desafortunadamente leyó el códice al revés, es decir, de derecha a izquierda, lo que ocasionó una serie de problemas en la paginación del manuscrito (figura 2).

Después de Brasseur el Troano fue estudiado por William Bollaert (1870), Daniel G. Brinton (1870), C. H. de Charencey (1876) y Cyrus Thomas (1882), pero no hubo mayores progresos sobre el orden de lectura de las páginas, hasta el descubrimiento del Cortesiano y que se probó que ambos fragmentos formaban parte del mismo documento (Rosny, 1882). El Cortesiano fue publicado posteriormente por De la Rada y Delgado (1893).

Esta edición, y la de Brasseur del Troano, fueron las que utilizó Ernst Förstemann (1902) para su estudio sobre el códice, señalando en él que se trata del fragmento más largo conocido de la literatura maya ( 56 hojas), pero también asienta:

Por otra parte, el Tro-Cortesiano es muy inferior al Dresde en limpieza y cuidado en la ejecución $|. .$.$| la falta de cuidado en la escritura del Tro-Cortesiano fue tan$ grande que sería inútil tratar de encontrarle un significado en todo lo que está registrado. El Dresde, en su totalidad, indica una cultura más ampliamente desarrollada por parte de la raza a la cual perteneció |... (Fórstemann, 1902: 5. La traducción es mía).

Como persona profundamente interesada en el calendario le llamó la atención el hecho de que en el Madrid no hubiera eventos astronómicos ni uso de cifras superiores a 20 , pues, cuando se encuentran, considera que éstas no tienen sentido, por ejemplo, en $M .8$ y M. 73 - 74a, quedando el códice confinado 
exclusivamente al uso del Tonalamatl, ${ }^{7}$ con lo cual se correspondería a la primera parte del Dresde $(1-45 \text { de Förstemann })^{\mathrm{g}}-\mathrm{y}$ los del Grupo Borgia-. Hace otras observaciones sobre los formatos de los dos códices y señala que:

Más observaciones [...] deberán hacerse antes de que podamos determinar con mayor exactitud las preguntas acerca de los lugares y las fechas de origen de los dos manuscritos. Pero, estoy convencido de que pertenecieron a dos lugares y períodos diferentes (Förstemunn, 1902: 6. La traducción es mía).

Años más tarde, cuando la Academia Graz (1967) publicara el códice, Ferdinand Anders, quien desde luego conoció el trabajo de Förstemann, repitió los mismos comentarios acerca de que "el cuidado y la limpieza en la ejecución del Códice Madrid es muy inferior a los otros dos" (Anders, op. cit.: 53), aunque él lo atribuye a la mano del autor.

En este sentido cabe señalar que el proyecto Códice Tro-Cortesiano del Museo de América de Madrid ha probado que en su ejecución participaron ocho. quizá nueve diferentes escribas (Lacadena, 2000), algunos de ellos bilinguies, pues hay evidencias en la escritura de palabras escritas en yucateco y ch'ol o ch'olano oriental (Vail, 2000: 56). Pero el problema sobre el lugar de origen y la fecha de ejecución de los códices aún permanece.

Eric Thompson (1972), en su obra A Commentary on the Dresden Codex, apoyándose en algunas fechas, temas y elementos del altiplano presentes en el libro (figura 3), propuso que éste pudo haber sido escrito en Chichén Itzá, aunque nunca explicó por qué la caligrafía del códice y la de los monumentos de esa ciudad son tan diferentes. El mismo autor señaló que el códice debió ser copia de un manuscrito más antiguo, por las fechas de Cuenta Larga escritas en él.

Al comparar el Dresde con el Madrid advirtió la ausencia de elementos mexicanos [?] en el segundo, así como el hecho de que los portadores de año son: Kan, Muluk, Ix y Kawak, correspondiendo a los descritos por Landa en el siglo xv. De ahí planteó que el Madrid podría proceder de la costa occidental, tal vez de Champotón y que habría sido escrito a mediados del siglo xv, con lo cual Victoria Bricker (1997; 2000), a través de otros estudios sobre el calendario de este mismo documento, coincide, pues ella propone para las páginas 27 a 29 del Madrid las fechas julianas de 1444 a $1482 \mathrm{~d}$. C.

Debido al hecho de que el Madrid tiene en una de sus páginas (M. 56) un pedazo de papel europeo con un fragmento de texto escrito en latín, Michael

\footnotetext{
${ }^{7}$ Con ese nombre se llamaba en náhuatl a esta clase de libros y por ello los primeros epigrafistas, e inclusive algunos modernos, los siguen designando con este término.

"En este trabajo utilizo la paginación actual de los códices Dresde y Madrid, es decir, la de Thompson (1983), que incluye las cuatro páginas en blanco. Para el Madrid me apoyo en la paginación de Förstemann (1902) y Thomas A. Lee (Los codices mayas, 1985), que va de corrido a lo largo de todo el códice.
} 
Coe y Justin Kerr (op. cit.: 181) han planteado que el códice tendría que ser del siglo xvin, específicamente de Tayasal (lo cual, según Thompson, no podria ser por los portadores de año).

Como reto a futuro del proyecto Códice Tro-Cortesiano está precisamente "el poder precisar cuándo se elaboró [...] su procedencia etnolinguística, su comportamiento con respecto a la información que se pretendia colocar en el libro, etcétera" (García Ruiz, 2000: 14) y, aunque Lacadena en un trabajo previo sostenía que: "posiblemente los códices no están muy separados temporalmente entre sí [...] probablemente, podamos considerar no más de ciento cincuenta años $[\ldots \mid$ de diferencia para sus respectivas facturas $[\ldots \mid$ pudiéndose efectuar en los siglos xv y xv" (Lacadena, 1995, citado por Garcia Ruiz, 2000: 18). Posteriormente, en compañía de Garcia Ruiz (2000: 22), concluyeron que: "desde un punto de vista cronológico, mantenemos nuestra impresión de que fue confeccionado entre el siglo xv y $x^{\prime \prime}{ }^{\prime \prime}$, lo cual implica el problema que me interesa discutir.

Todos los epigrafistas aceptan que el Códice de Dresde es copia de un manus: crito anterior, posiblemente del Clásico. De acuerdo con Thompson debió haberse escrito ca. 1200 y 1300 d.C., lo que está muy lejos de las fechas propues. tas para el Madrid por el grupo español y los norteamericanos. Enfatizo este punto porque hay varias partes del Madrid que son casi iguales a algunas del Dresde.

David Kelley, en su libro Deciphering the Maya Script (1977: 249-250), en el capitulo dedicado al análisis de estructuras de textos, señaló la existencia de cuatro pasajes paralelos en ambos códices (figuras $4 \mathrm{a}, 4 \mathrm{~b}, 4 \mathrm{c}$ y $4 \mathrm{~d}$ ) -el término paralelo me parece de lo más apropiado porque nunca se juntan-. En realidad se trata de textos casi idénticos, salvo que en el Madrid están escritos en forma más breve, pero las fechas son esencialmente las mismas. Existen además otros textos en el Madrid que tocan los mismos temas que los del Dresde, aunque por tener fechas distintas no los incluyo.

Debo señalar que no voy a hablar de todo el códice, solamente me referiré a dos secciones del documento - que prefiero llamar capitulos-, localizados en la primera parte del Madrid, misma que Förstemann señalara como la más parecida al Dresde.

Los códices han sido divididos por los epigrafistas en secciones, pero yo opino que se trata de capítulos, definidos por los signos-dias del Almanaque Sagrado, Tz'olkin, o Año de 260 días, lo cual hasta el momento me parece que no ha sido reportado por ningún otro epigrafista. ¿En qué consiste esta separación? En que cada vez que hay un cambio de capitulo, o tema, los signos-dias del Tz'olkin están alineados a lo largo del lado izquierdo del observador (figura 5). y esto aunque es mucho más obvio en el Madrid, también se aplica al Dresde. Ninguno de nuestros códices comienza asi, lo que refuerza el hecho de que son fragmentos de manuscritos más grandes y, además, que fueron planeados en su ejecución con todo cuidado. 
¿Qué implica lo anterior? Que los sacerdotes sabian, con precisión, en qué libro y en qué capitulo estaban las respuestas a sus preguntas, y por eso hay textos paralelos en los códices. Pero también es importante para nuestro estudio porque nos aproxima a la manera como pudo ser su uso por parte de los mayas.

Tomemos como ejemplo la "Sección de las mujeres" en el Dresde. Todos los epigrafistas señalan como inicio de dicho capitulo la página 15 , si mi propuesta es correcta, en realidad comienza en la página 13 y continúa hasta la 23 . El capitulo anterior incluye de la 4 a la 12 .

Volviendo a los pasajes paralelos, resulta muy interesante que uno de los textos de la última página del Dresde (73 - 74) sea igual al del Madrid en 2 b; las imágenes representadas son tapires, y por la asociación con los numerales (ciclos de 780 días o múltiplos de 78 ) se le ha llamado la Bestia de Marte (figuras 6a y 6b).

Los números son los siguientes: ${ }^{9}$

$\begin{array}{lllllllll}\text { D. } 73-74 & 19 & 9 & 19 & 2 & 19 & 8 & 21 & 3 \\ \text { M. } 2 \text { b } & 19 & 9 & 19 & 2 & 19 & 8 & 19 & 3\end{array}$

Como puede observarse, los números distancia y los acompañantes de los días son casi los mismos, además los textos del Dresde están compuestos por seis cartuchos e inician con el verbo ch'a-ka-ha, ch'akah, "cruzó sobre", al que sigue el glifo nominal del dios. En el Madrid solamente hay dos cartuchos para cada oración, pero también está el verbo ch'a-ka, y en lugar del nombre del dios se encuentra el glifo nominal del dios C, que por alguna razón fue muy importante para los autores de este libro. Ante dicha evidencia comienza uno a preguntarse ¿por qué se repite el texto?, si, como dicen los epigrafistas, ambos libros fueron ejecutados en épocas y sitios muy distantes entre sí. 20 es que habia libros base que eran copiados según los intereses de cada ciudad? Pasemos a los otros casos.

El siguiente texto lo asocié por el ND (65), deidad (Chaak), puntos cardinales (como los designamos nosotros) y ofrendas. En M. 2c - 3c están dos dioses Chaak, se trata del final de un texto, como puede comprobarse por D. $62-63$, en donde se repite (figuras 7 a y $7 \mathrm{~b}$ ). Los números distancia en Dresde suman 64 , aunque debió ser 65, como está en el Madrid, donde está escrito con tres signos de completamiento (20) y una barra (5). Del texto solamente se conservó un cartucho no descifrado y los puntos cardinales, en la escena se pueden observar los animales que se ofrendaban: un venado y una iguana.

Y si hablamos de minimizar la información en el Madrid, el siguiente texto es más sorprendente. Se trata de D. $60-64$ y $M$. 3a - 6a (figuras $8 \mathrm{a}$ y $8 \mathrm{~b}$ ). Los númerales están como sigue:

\footnotetext{
${ }^{9}$ Para propósitos de claridad he dejado en negritas lo que llamamos Números Distancia (ND), los otros corresponden a los números rojos de los códices. Nótese que en el Madrid hay un error en el último, dice 19 y deberia ser 21. Como éste hay varios casos en el Madrid.
} 

D. $60 \cdot 64^{10}$
10 ben
10 edznab
$[10]^{11}$ akbal
10 lamat
M. $3 a-6 a$
10 edznab
10 akbal
10 lamat
10 ben

Como puede observarse, en el Madrid el texto se redujo a: punto cardinal, Chaak y algo más, juntaron en una imagen al dios y a la serpiente (que conserva el mismo numeral), y solamente anotaron el primer y el último día. El capitulo termina en la página 9.

El siguiente capitulo va de la 10 a la 19 y en $M$. 10a - 13a se encuentra otro de estos pasajes paralelos que se corresponde con $D .67 \mathrm{~b}-70 \mathrm{~b}$ (figuras 9a y 9b). los números están así:

$$
\begin{aligned}
& \text { D. } 6+16=9+8=4+11=2+10=12+1=13+12=12+6=5+12=4+11=2+11=13+6 \\
& \text { M. } 6+16=9+8=4+3=7+10=4+1=5+12=4+6=10+12=9+\quad 2
\end{aligned}
$$

Entre ambos pasajes existen diferencias, tanto en los numerales como en las imágenes. El primer cambio está en el tercer ND, en lugar de 11 está 3 (faltarían 8), pero pienso que esto fue hecho a propósito para cambiar los números acompañantes de los dias, y a los dias. Es evidente que los autores del Madrid prefirieron otras fechas, lo que explicaria los cambios detectados en los otros textos. Además, no pusieron, posiblemente por error, la penúltima imagen: la del Pawahtun, con lo cual el penúltimo y último ND se tienen que reconstruir. Esto desde luego no sería problema para un sacerdote conocedor del códice, pero uno se pregunta Lpor qué no se corrigieron, en ningún caso, dichas anomalias, evidentes, en el calendario? ¿Podría ser que el escriba no supiera lo que estaba escribiendo?

Existe otro pasaje paralelo más adelante, se trata de un texto asociado con la diosa I, la Luna joven (figuras 10a y 10b), y es muy interesante ver cómo está trabajado el mismo texto en los dos códices:

$$
\begin{array}{ll}
\text { D. } 21 \mathrm{~b} & 7+7=1+7=8+7=2+5=7 \\
\text { M. } 90 \mathrm{c}-92 \mathrm{c} & 7+7=1+7=8+7=2+5=7
\end{array}
$$

En ambos casos el calendario es idéntico, lo que se llama un tzolk'in doble, las oraciones del Dresde relatan las relaciones - y atan |?], "su esposa" - entre la diosa con: un dios (Itzamnah) y varios animales (perro, armadillo y venado). aunque solamente hay una imagen, mientras que en el Madrid están representados todos, pero los textos hablan de casas fisicas (otot). ¿Será otra manera de indicar las relaciones entre la diosa y sus acompañantes?

\footnotetext{
${ }^{10}$ No voy a incluir todo el desarrollo del Almanaque, solamente presento la última Fecha Diuma del Dresde, que es como se encuentra en el Modrid.

it Está reconstruido porque dice 11.
} 
Hasta la página 19 del Madrid podemos hablar de un libro religioso, sagrado, en el sentido de que se ocupa básicamente de actividades propias de los dioses, como ocurre en casi todo el Dresde, pero a partir de la página 20 el Madrid cambia, se humaniza, las imágenes representadas siguen siendo los dioses, sin embargo ahora se les puede ver en diligencias relacionadas con las actividades cotidianas de los seres humanos.

Apoyándome en la distribución del calendario en el códice, es decir, los capitulos y temas tratados en êl (figuras 11a y 11 b), he empezado a dividirlo de la siguiente forma:

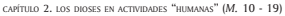

1. M. $10 \mathrm{a}-13 \mathrm{a}(c f . \mathrm{CD})$

2. M. 10b-11b, Dios B, lluvia y siembra. Diosa O

3. M. $10 \mathrm{c}-11 \mathrm{c}$ (cf. CD), los asientos del dios C

4. M. $12 \mathrm{bc}$, Dios B

5. M. 13 bc - 18 bc, serpientes de la lluvia

6. M. 14a, dioses en templos

7. M. 15a, dioses en templos

8. M. 16a, dioses en templos

9. M. 17a, Zentierros?

10. M. 18a, 2llegadas/ nacimientos?

11. M. 19a, Lllegadas/ nacimientos?

12. M. 20a, 2llegadas/ nacimientos?

13. M. $19 \mathrm{bc}$, autosacrificio con cuerda

(posible final de capitulo)

CAPITULO 3. LAS ACTIVDAdES ARTISTICAS (M. 20 - 23)

14. M. 20b1-21b3, Ltumbas?

15. M. 20c, siembra

16. M. 21c, Ltocados?

17. M. 21a1-22a1, ¿tambores?

18. M. 22b. 2tambores?

19. M. $22 \mathrm{C}$

20. M. 20d1-21d1, Lsonajas?

21. M. $21 \mathrm{~d} 2-22 \mathrm{~d} 3$, ¿sonajas?

22. M. 22a2 - 23a5, Lsonajas?

23. M. $22 \mathrm{~d} 4-23 \mathrm{~d} 2$, pintores

24. M. 23 c, pintores

25. M. 23b2 -3

(termina capitulo)

CApituLO 4. LA SIEMBRA (M. 24 - 28)

1. M. $24 a$, la cosecha 
2. M. 25a, la cosecha

3. M. $24 \mathrm{~b}$, nacen las plantas

4. M. $25 \mathrm{~b}$, nacen las plantas

5. M. $24 c$, los rituales para la siembra

6. M. $25 c$, los rituales para la siembra

7. M. 24 d, la siembra

8. M. 25 d, la siembra [¿de abajo hacia arriba?]

9. M. 26a - 27a2, los dioses de la siembra: los Pawahtún y Chaak

10. M. 26b $-27 \mathrm{~b} 2$, los dioses de la siembra: los Pawahtún y Chaak

11. M. $26 c-27 c 2$, las aves sagradas y el dios del maíz

12. M. $26 \mathrm{~d}-27 \mathrm{~d} 3$, los cuidados y peligros de la siembra del maiz

13. M. 27a3 - 28a, Dios del maiz con numerales en el cuerpo (cf. M. 73a - 74a)

14. M. $27 \mathrm{~b} 3-28 \mathrm{~b} 3$, los cuatro dioses de la lluvia y la milpa [úa cosecha?]

15. M. $27 c 3-28 c 3$, el dios de maíz y la milpa [imaiz sembrado?]

16. $M .28 \mathrm{~d}$, la semilla del maíz [2de abajo hacia arriba?]

(termina capitulo)

Apoyándome en las dos primeras páginas que inician el capítulo dedicado a la agricultura en el Códice Madrid, explicaré el que pienso pudo ser el uso de estos libros y cómo eran consultados. Veamos las páginas $24-28$ del códice (figuras $11 \mathrm{a}$ y $11 \mathrm{~b})$.

El año de 260 días, en los códices, se divide en grupos de 52 días, lo cual nos da cuatro grupos de cinco días cada uno que no varían, siempre son los mismos y mantienen un mismo orden inalterable (salvo que haya un error), pero el Almanaque puede comenzar por cualquiera de ellos, y los otros simplemente siguen su orden acostumbrado. A veces esta división se subdivide y entonces los ND suman 26 dias, por eso los llaman calendarios dobles.

Existe otra división entre 65 , con lo cual tenemos cinco grupos de cuatro días, que igualmente son constantes y no alteran su orden. Estos grupos, por razones matemáticas, conforman también los llamados días Portadores o Kuch Haab, y están representados en los tres códices.

Sabemos que la escritura maya en monumentos se lee, regularmente, por columnas dobles, de izquierda a derecha y de arriba hacia abajo, por eso siempre hemos seguido este orden en los códices; pero ahora me parece que hay evidencias para pensar que éste no era tan rígido en los libros. No me refiero a la conformación interna de los textos sino a la página misma. La verdad es que no sabemos qué orden se seguía en la lectura dentro de las páginas, ni estamos seguros de que lo hubiera.

Mi opinión es que no lo habia, porque finalmente cada almanaque es un texto cerrado. No tienen continuidad en la lectura porque no son párrafos de un libro. Se trata en cada caso de un año de 260 días completo, cuya función era la de proporcionar las fechas positivas y las negativas ante determinados eventos. Nacimientos, bautizos, matrimonios, enfermedades, enterramientos, ca- 
cería de determinados animales, pesca, agricultura, guerra, fabricación de máscaras, tocados, vasijas, instrumentos musicales, etcétera. Todo estaba regido por el ciclo de 260 días, pues era el que nombraba al dia, y éste nunca cambió a lo largo de la historia mesoamericana. Los díoses-dia y sus acompañantes, los dioses-número, los de la trecena, nunca interrumpieron su diario peregrinar.

Por eso era tan importante saber quiénes estaban rigiendo "ese día específico", para que si no era positivo se buscara la forma de cambiarlo, y esa era la función de los cuidadores del tiempo, los $\mathrm{Ah} \mathrm{K}$ in.

Observemos las imágenes de las páginas 24 y 25 del Madrid, sin tomar en cuenta el año de 260 días, simplemente veamos las figuras de abajo hacia arriba. En la M. 24d están: Chaak plantando, el dios del maíz en la tierra comido por gusanos y por aves, después figura otra vez Chaak plantando. En $M$. 25d están el dios del maiz y el perro, asociados a los puntos cardinales, sentados sobre la tierra. Bricker identificó este pasaje como el periodo de resiembra y. aunque cambien los días, los numerales del tzolk in son los mismos en estos dos casos:

$\begin{array}{llllllll}13 & 4 & 13 & 4 & 13 & 4 & 13 & 4\end{array}$

En la sección inmediata superior, $M .24 c-25 c$, el almanaque se continúa, es uno solo, con lo cual se confirma que estas páginas se leen juntas. Nuevamente está el dios del maiz: muerto, vivo, vivo, muerto. Es obvio que ese es el peligro que corre el dios, y es probable que estos sean los rituales llevados a cabo para protegerlo mientras está sembrado, hay dias positivos y hay dias negativos.

Siguiendo hacia la línea superior, M. $24-25$ b, (ND 26 y 52), tenemos que las plantas ya crecieron, en la página 24 el verbo se lee mu-lu, mul, "amontonar, juntar", y los actores de la acción, pero en la 25 solamente está escrito: LUK y el sujeto de la acción.

La línea superior es muy clara, los dioses están cosechando, pero a diferencia del Códice de Dresde donde por lo regular el verbo se repite, aquí las oraciones son diferentes.

Existen otros textos que también se leen de abajo hacia arriba, los casos más claros son las páginas de portadores de año, en Dresde y Madrid, donde las ceremonias para los dias wayeb/wayayeb están en la parte inferior, lo que además indica que si se llevaban a cabo ciertas actividades, arriba están las relativas al nuevo año. Otro ejemplo es la llamada Tabla de múltiplos de 78 en Dresde, también se lee de derecha a izquierda y de abajo hacia arriba.

Pienso haber probado con lo anterior que el orden de lectura en los códices es por almanaques y está en relación con lo que se iba a consultar, por eso hay capitulos y dentro de ellos están los diversos temas. 


\section{Conclusiones}

He tratado de demostrar que el Códice Madrid es una copia, aunque breve en sus textos y diferente, pero al fin copia, de muchos pasajes que se encuentran en el Dresde. Me aventuro a suponer que la ciudad a la que estuvo destinado el Códice Madrid tenia propósitos más allegados a la vida cotidiana, pero sabian y conocian perfectamente cómo funcionaba el año de 260 días, de hecho lo llegaron a manejar mucho más audazmente que los autores del Dresde, al igual que los autores de los códices del Grupo Borgia.

Parecería que quienes escribieron el Códice Madrid no sabian mucho respecto a los números ya que, como dijo Förstemann, tiene errores (numéricos), pero sólo, o especialmente, en las páginas donde no hay textos escritos. ${ }^{12} \mathrm{Y}$ aquí me atrevería a preguntar: Llos escribas de los códices no se daban cuenta de sus errores matemáticos? Porque están tanto en el Dresde como en el Madrid.

Y, para finalizar, si el Madrid fue escrito en los siglos xv-xvi, en Tayasal, Champotón, u otro lugar, ¿cuál fue la copia del Dresde que estaban copiando? o Les que había libros básicos para el ceremonial y libros de consulta para las actividades propias de cada población?

Y, lo que más me interesa, ¿por qué cambiar al dios? Los usuarios del Dresde necesitaban a Chaak, los del Madrid lo sustituyeron por el dios C, deidad verdaderamente interesante durante el Clásico, que sabemos identifica el Ch'ul/ K'uh/ K'uh-ul: lo sagrado o divino, y que podría ser un alter ego del dios solar, como puede apreciarse en varias inscripciones (Placa de Leyden, dintel 48 de Yaxchilán), donde dicho animal sustituye al glifo para K'in, sol o día. Si no hay, aparentemente, más textos paralelos entre ambos códices, puede deberse a que el Madrid fue escrito para una población, o un sector de ella, con las actividades humanas propias de cualquier pueblo maya, mientras que el Dresde está dirigido a un grupo cuyo principal interés era la astronomía.

De todas maneras, permanece el hecho de que los códices Dresde, Madrid y Féjérvary-Mayer son copias de algún o algunos otros libros, que por desgracia no conocemos, como tampoco nunca sabremos si había escuelas para los futuros ah $T z^{\prime} i b^{\prime} o o b$ '.

\section{BIBLIOGRAFÍA}

Anders, Ferdinand

1967 Codex Tro-Cortesianus (Códex Madrid), Museo de América de Madrid. Graz, Austria: Akademische Druck-und Verlagsanstalt.

\footnotetext{
${ }^{12}$ No he comparado la relación entre estos textos y los escribas identificados por Lacadena.
} 
Bill, Casandra, Christine Hernández y Victoria Bricker

2000 "The relationship between early colonial Maya new year's ceremonies and some almanacs in the Madrid Codex", Ancient Mesoamerica (11): 149-168, EUA: Vanderbilt University.

Bollaert, William

1870 "Examination of Central American hieroglyphs of Yucatan. Including the Dresden Codex, the Guatemalien of Paris and the Troano of Madrid; the hieroglyphs of Palenque, Copán, Nicaragua, Veraguas and New Granada, by the recently discovered Maya alphabet", Memoires, 150: 288-314. Londres: The Anthropological Society of London.

Brasseur de Bourbourg, Charles Ettienne

1869-1870 Manuscrit Troano. Etude sur le systeme graphiq̨ue des Mayas, París, 2 vols.

Bricker, Victoria

1997 "The "calendar-round'almanac in the Madrid Codex", Papers on the Madrid Codex, 64:169-180, V. Bricker y G. Vail (eds.). EUA: Tulane University, Middle American Research Institute (Publication 64).

2000 "Bilingualism in the Maya codices and the books of Chilam Balam", Written Language and Literacy, 3 (1): 77-115. EUA: John Benjamins.

Brinton, Daniel G.

1870 "The ancient phonetic alphabet of Yucatan", American Bibliopolist, II: 143148. Nueva York: J. Sabin and Sons.

Charencey, C. H. de

1876 Recherches sur le Codex Troano. Paris: Actes de la Societé Philologique.

Coe, Michael y Justin Kerr

1997 The art of the Maya scribe, Nueva York: Harry N. Abrams.

Códices mayas, Los

1985 Introducción y bibliografia por Thomas A. Lee Jr. Chiapas: Universidad Autónoma de Chiapas.

Förstemann, Ernst

1902 Commentar zur Madrider Maya-Handschrift (Codex Tro-Cortesianus). Danzig [Existe una traducción al inglés, mecanografiada, en la Biblioteca Rubén Bonifaz Nuño del IIFL.].

Garcia Ruiz, Andrés

2000 "El códice Tro-Cortesiano del Museo de América de Madrid", Revista Española de Antropologia Americana, 30: 9-25. Madrid, Universidad Complutense. 
Humboldt, Alexander von

1810 Sitios de las cordilleras y momumentos de los pueblos indigenas de América, en Obras completas de Alejandro de Humboldt. Madrid: Imprenta de Gaspar. (1878).

Kelley, David H.

1977 Deciphering the Maya script. Austin y Londres: University of Texas Press.

Lacadena, Alfonso

2000 "Los escribas del Códice Madrid. Metodologia paleográfica", Revista Española de Antropología Americana, 30: 27-85. Madrid: Universidad Complutense.

Rada y Delgado, Juan de Dios de la

1890 "Le Codex Troano et le Codex Cortesianus", en Congreso de Americanistas, VIII: 652-653, Paris.

1893 Códice maya que se conserva en el museo arqueológico nacional, reproducción fotocromolitográfica. Madrid.

Rosny, León de

1882 Les documents écrits de l'antiquité américaine. Paris: Maisonneuve.

Thomas, Cyrus

1882 "A study of Manuscript Troano", en Contributions to North American Ethnology, V: 1-237. Washington: Department of Interior.

Thompson, J. Eric S.

1962 A Cafalog of Maya Hieroglyphs. Norman: University of Oklahoma Press.

1972 A Commentary on the Dresden Codex. A Maya Hieroglyphic Book. Philadelphia: American Philosophical Society (1983).

1988 Un comentario al Códice Dresde. México: FCE.

Vail, Gabrielle

2000 "Issues of language and ethnicity in the Postclassic Maya codices". Written Language and Literacy, 3 (1): 37-75. EUA: John Benjamins.

Zimmermann, Günter

1964 "La escritura jeroglifica y el calendario como indicadores de tendencias de la historia cultural de los mayas", en Desarrollo cultural de los mayas: 229 242. México: UNAM, Seminario de Cultura Maya. 


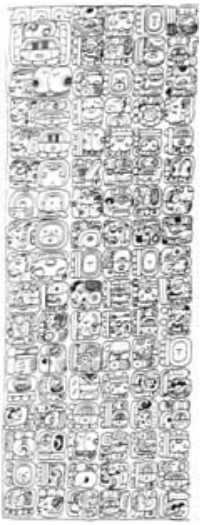

Figura 1a. Theiero de la Guzz. Dibujo de Linda Schele

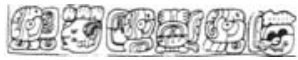

Figura 1b. Tabizso de la Cruz. Detalle Dibujo de Linda Schele 


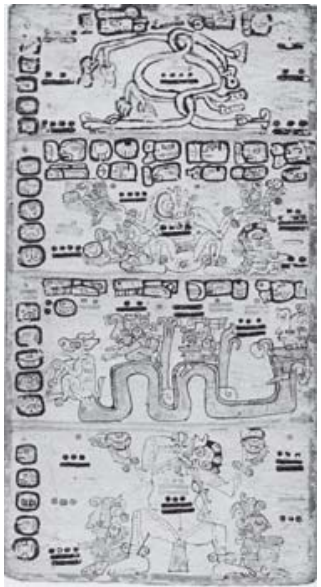

Figurs 2. M. 29

Los códices mayos 


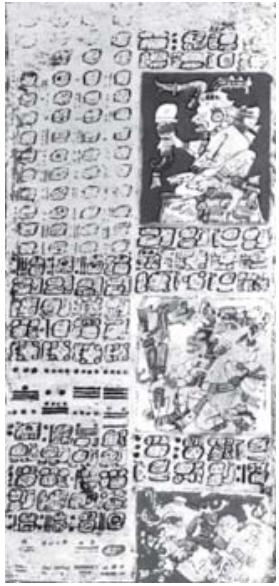

Figurs 3. D. 27

Los códices mayas 

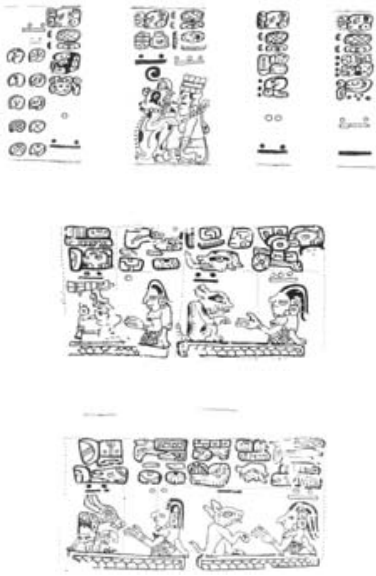

Fucara 4a. Mujeses

Kelly. 1977 

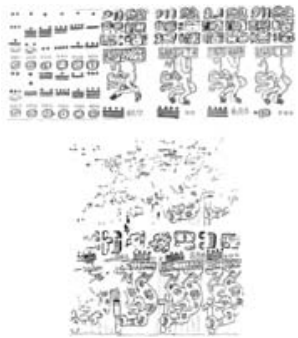

Ficura 4b. Bestia de Marte

Kelly. 1977
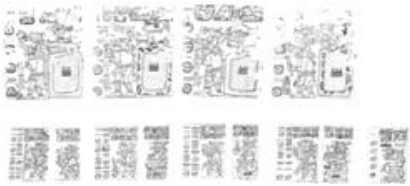

Ficuins 4c. Dios Chrnx

Kelly. 1977 


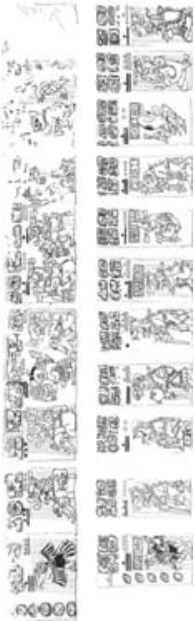

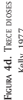




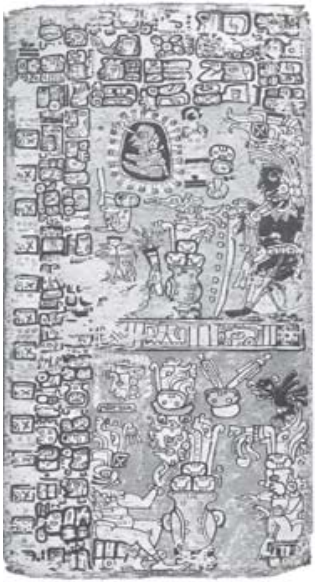

Figura 5. M. 34

Los códices mayos 


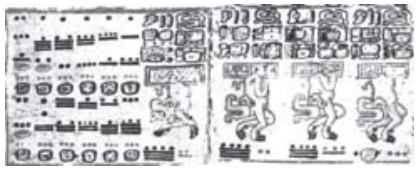

Fucuгn 6a. D. 73 - 74

Los códices mayos

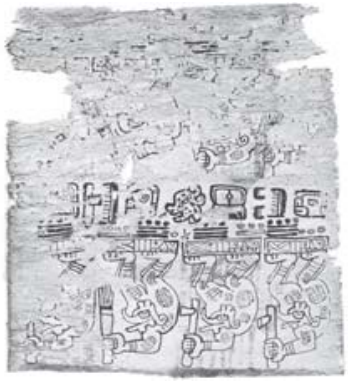

Ficure 6b. M. 2b

Las coidices mayas 


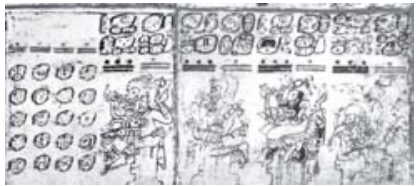

Ficurs 7a. D. $62-63$

Las códices mayas

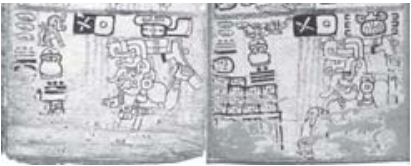

Figura 7 b. M. $2 \mathrm{c}-3 \mathrm{c}$

Los codices mayas 

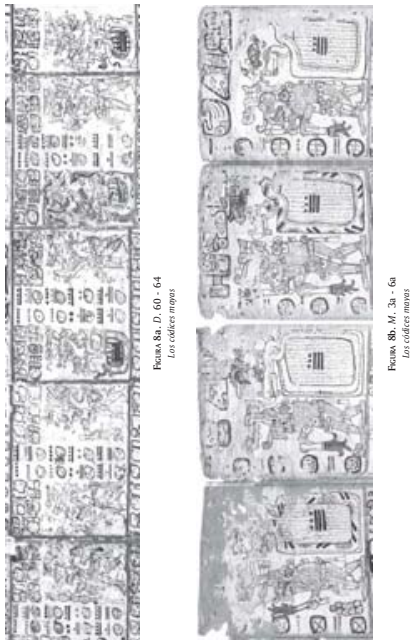

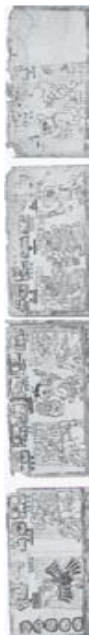

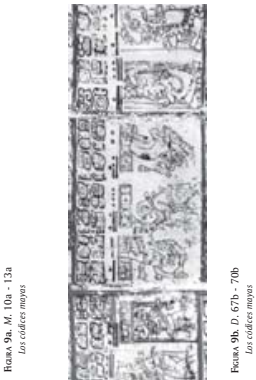

m

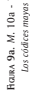



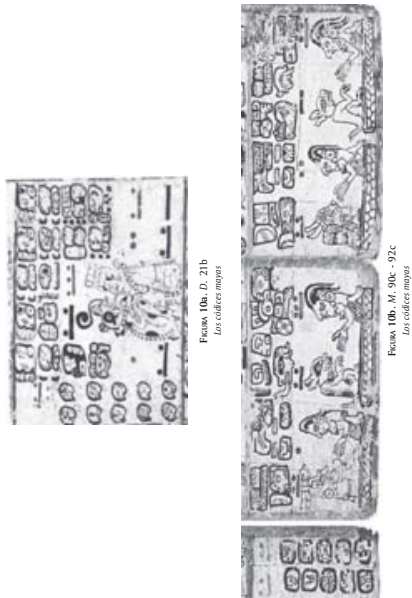

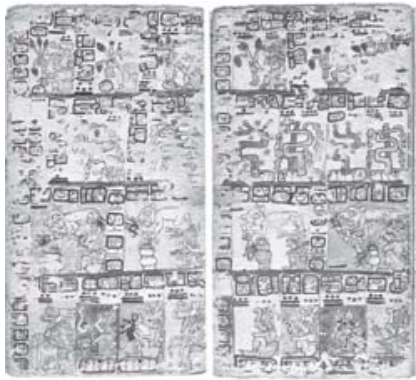

Figura 11a. M. 24 - 25

Los codices mayos 


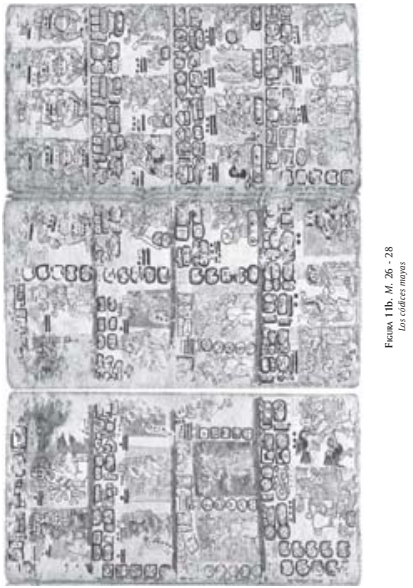

